\title{
Gambling Behavior Among Underage Adolescents in Hong Kong
}

\author{
Irene Lai Kuen Wong* \\ Department of Applied Social Sciences, The Hong Kong Polytechnic University, \\ Hung Hom, Kowloon, Hong Kong \\ *Corresponding author; email: ssilkw@inet.polyu.edu.hk
}

\begin{abstract}
This study examined the prevalence of gambling involvement and pathological gambling among students aged 12 to 17 years in Hong Kong, and investigated the correlates of problem gambling. The DSM-IVMR-J was administered to 1,121 students. The response rate was $89.3 \%$. Sixty percent of the participants gambled in the previous year, $69 \%$ were infrequent players who bet less than 4 times a month, and $4.8 \%$ gambled at least once a day. Most (89.8\%) wagered less than HK\$100 a week, only 3.1\% staked over $\mathrm{HK} \$ 500$, and $24 \%$ borrowed money to finance their gambling activities. The majority $(78.6 \%)$ had started gambling before the age of 15 years. One-fifth $(21.5 \%)$ transferred gambling payments at the betting venues, $44.7 \%$ were assisted by their parents and $19.7 \%$ were helped by peers. Using the DSM-IV criteria, $3.4 \%$ and $1.8 \%$ of the participants could be classified as pathological and problem gamblers, respectively. Significant gender $\left(\chi^{2}(1)=8.3, p<0.01\right)$ and age differences $\left(\chi^{2}(7)=21, p<0.01\right)$ were noted for such gambling addiction. Pathological and problem gambling were significantly correlated with age $(r=0.44, p<0.01)$, gambling frequency $(r=0.41, p<0.001)$, gender $(r=0.33, p<0.01)$, early initiation $(r=-0.31, p$ $<0.05)$, psychiatric disturbances $(r=0.25, p<0.001)$, as well as parents $(r=$ $0.21, p<0.01)$ and peers $(r=0.18, p<0.05)$ having gambling problems. The findings have implications for preventive initiatives.
\end{abstract}

Key words Adolescents - Gambling Addiction - Correlates P Prevention . School Survey

\section{Introduction}

Underage gambling is illegal but widespread among adolescents in many jurisdictions (Derevensky \& Gillespie, 2005). Prevalence studies show that 60 to $80 \%$ of teenagers aged under 18 years have engaged in at least one form of gambling activity in the preceding year (Adlaf \& Ialomiteanu, 1999; Delfabbro, Lahn, \& Grabosky, 2005; Gillespie, Derevensky, \& Gupta, 
2007; Griffiths, 1989; Jacobs, 2000, 2004; National Research Council, 1999; Olason, Skarphedinsson, Jonsdottir, Mikaelsson, \& Gretarsson, 2006; Stinchfield \& Winters, 1998; Turchi \& Derevensky, 2006; Welte, Barnes, Tidwell, \& Hoffman, 2008). Surveys conducted in Australia (Delfabbro et al., 2005) and Canada (Gupta \& Derevensky, 1998a) revealed that as many as $35 \%$ of underage youths wagered with money at least once a week. With increasing availability and accessibility of legalized gambling activities, the risk of underage gambling involvement and pathological gambling may proliferate.

Most teenagers gamble for enjoyment without suffering any harmful consequences, although a small but significant proportion gamble excessively, and endure severe personal, financial, educational, social and mental health problems (Jacobs, 1993, 2000; Shaffer \& Hall, 1996; Stinchfield \& Winters, 1998; Turchi \& Derevensky, 2006). The past-year estimates of pathological gambling among adolescents are relatively high, ranging from 2 to $9 \%$ (median, 6\%) in the United States (Shaffer \& Hall, 1996, 2001; Volberg \& Moore, 1999) and in Canada (Gupta \& Derevensky, 1998a; Ladouceur, Dubé, \& Bujold, 1994; Wynne, Smith, \& Jacobs, 1996). Similar rates have been reported in Australia (Delfabbro et al., 2005; Moore \& Ohtsuka, 1997) and many European countries including the United Kingdom (Fisher, 1993, 1999; Griffiths, 1995). Gender differences were found with respect to adolescent gambling problems. The National Research Council (1999) reported lower prevalence rates (0.5-1.8\%) for severe gambling problems in adolescent girls. Adolescent boys appear to be more vulnerable to pathological gambling (Jacobs, 2004) than their female counterparts.

A review of literature indicates the following demographic, behavioral and psychosocial factors may signal greater risk for developing excessive gambling among teens: being male, coming from a minority ethnic group, having poor academic results, early initiation, diverse or frequent gambling involvement, borrowing money to gamble, wagering relatively large amounts of money, having parents and friends who gamble, exhibiting regular substance use, having a history of delinquency or antisocial behavior, and experiencing psychiatric comorbidity such as depression (Desai, Maciejewski, Pantalon, \& Potenza, 2005; Fisher, 1993; Griffiths \& Wood, 2000; Gupta \& Derevensky, 1998a, 1998b; Jacobs, 2000; Nower, Gupta, Blaszczynski, \& Derevensky, 2004; Winters, Stinchfield, \& Fulkerson, 1993a). Information on correlates of pathological gambling in adolescents is very useful for identifying young problem gamblers. Such data also throw light on the development of empirically based awareness and prevention programs (Jacobs, 2004).

In the last decade, local researchers have been concerned about problem gambling among adolescents, especially after legalization of soccer betting in Hong Kong in 2003. Several studies of gambling behavior among adolescent students have been conducted (e.g., Hong Kong Polytechnic University, 2001; University of Hong Kong, 2005; Wong \& So, 2004; Wong, 2006). The past-year rates for adolescent gambling recorded were $53.8 \%$ in 2001 (Hong Kong Polytechnic University), 48\% in 2004 (Wong \& So), 34\% in 2005 (University of Hong Kong), and 53.3\% in 2006 (Wong). In the 2001 government-commissioned survey (Hong Kong Polytechnic University) that used the Diagnostic and Statistical Manual of Mental Disorders $-4^{\text {th }}$ 
edition (DSM-IV) criteria (American Psychiatric Association, 1994), 2.6\% and 4.5\% of a sample of 2,000 students aged 12 to 18 years were categorized as pathological and problem gamblers, respectively.

In the 2005 government-sponsored survey (University of Hong Kong) of a sample of 1,496 students aged 12 to 19 years, $1.3 \%$ each were classified as pathological and problem gamblers. Using the South Oaks Gambling ScreenRevised for Adolescents (Winters, Stinchfield, \& Fulkerson, 1993b), 2.8\% of a sample of 994 teenagers could be designated as pathological gamblers (Wong \& So, 2004). A rising prevalence rate of pathological gambling (3.2\%), assessed by the DSM-IV criteria, was reported by Wong (2006) in a school-based survey of 1,009 students (aged 12-17 years).

These Hong Kong studies expand our understanding of gambling behavior among teenagers. However, local research has rarely investigated gender differences or correlates of adolescent (underage) gambling. The legal age for gambling in Hong Kong is 18 years. Although legislation prohibits the participation of underage persons in government-regulated gambling activities, they successfully wager at legal and illegal outlets without difficulty (Hong Kong Polytechnic University, 2001; University of Hong Kong, 2005).

The present study aimed at gauging prevalence estimates of gambling involvement and pathological gambling among underage students aged 12 to 17 years. This survey also aimed to examine gender differences in underage individuals engaging in gambling activities. It was hypothesized that there would be gender differences in game preferences, age of starting gambling, reasons for involvement with gambling, and prevalence rates for gambling and pathological gambling. A further purpose was to identify demographic, social, behavioral and mental health factors associated with underage pathological gambling. The survey findings shed light on educational and preventive initiatives.

\section{Method}

\section{Participants}

A grade 7 to 11 class was randomly selected from each of the eight schools which joined this study. The survey was conducted during the summer term of 2008. A standardized questionnaire was distributed to 1,121 underage students but only 1,001 completed questionnaires were returned, giving a response rate of $89.3 \%$ on which the data analysis was carried out.

All the participants aged 12 to 17 years $(M=13.8, S D=2.1)$, and $551(55 \%)$ were boys. None had reached the legal gambling age in Hong Kong.

\section{Procedures}

An invitation letter outlining the survey purposes and procedures was sent to the 10 randomly selected schools (chosen from a school list). School principals from eight schools gave support to the study. A research assistant visited the schools, and monitored the questionnaire completion process during the classes. The survey objectives and procedures were clearly explained before the students' consent to participate was obtained. Participation was voluntary and anonymous. 


\section{Measures}

The self-administered questionnaire included the following sections:

1. A Demographic section on gender, age, school grades, and sources of pocket money;

2. A Gambling Behavior section asked participants if they had gambled during the previous 12 months, their gambling motives, choices of games, amount of money wagered and frequency of playing. Among those who admitted gambling, information was also collected on when and who taught them to make the first bet, and if their parents and peers had ever had gambling problems;

3. The Diagnostic and Statistical Manual- (4 $4^{\text {th }}$ Edition) - Multiple Response format for Juveniles (DSM-IV-MR-J) (Fisher, 2000) assessed the severity of gambling problems among adolescents. It is a reliable measure (Cronbach's alpha $=0.75$ ) with one principal factor being found. Endorsement of four or more of the nine categories of the criteria indicates pathological gambling, identification of two or three categories suggests problem gambling, and endorsement of zero or one category implies social or recreational gambling;

4. The 12-item General Health Questionnaire (GHQ-12) developed by Goldberg (1972) was used to assess mental health status. The brevity of the screen was particularly suitable for research such as this survey in which mental health was measured as one of the several variables. The questionnaire has been tested to be reliable (Cronbach's alpha $=0.86$ ) and valid (Banks et al., 1980; Goldberg et al., 1997). Using the GHQ-12 scoring method (0-0-1-1), the total scores range from 0 to 12 . As scores increase above the threshold, the poorer is the mental health status. As recommended by health researchers (e.g., Hodge, 1994), a more restrictive cutoff score of 3 (instead of 2) for detecting a case was adopted to minimize false positives.

Both the DSM-IV-MR-J and the GHQ-12 were translated into Chinese and then back translated into English by a bilingual therapist. The standardized questionnaire was written in Chinese, and a pilot test was conducted in a class of 30 students before the main study was undertaken.

\section{Results}

\section{Gambling involvement and pathological gambling}

Sixty percent of the participants (406 boys and 195 girls) had gambled in the preceding year. Using the DSM-IV criteria, 3.4\% $(n=34)$ of the entire sample could be classified as pathological gamblers, $1.8 \%(n=18)$ could be categorized as problem gamblers, and $54.8 \%(n=549)$ were social or recreational gamblers.

\section{Age differences}

A great majority of the social gamblers $(87 \%)$ were between 12 and 14 years $(M=$ 13.6, $S D=2.2$ ). Excessive gamblers (pathological and problem gamblers combined) had a mean age of 15.5 years $(S D=1.9)$ and were significantly older than the social gamblers $\left(\chi^{2}(7)=21, p<0.05\right)$. 


\section{Gambling frequency}

Many gamblers were infrequent players who bet once a month (41.9\%); $27.1 \%$ played 2 to 3 times a month, 23.7\% wagered 1 to 3 times a week, 2.4\% played 4 to 6 times weekly, and $4.8 \%$ gambled at least once everyday. On average, social gamblers played 0.8 times a week, whereas excessive gamblers wagered 4.6 times a week. Excessive gamblers gambled significantly more frequent than social gamblers $(t=$ $1.97, p<0.05)$.

\section{Money wagered on gambling activities}

For the entire sample of gamblers $(N=601), 89.8 \%$ wagered less than HK\$100 a week; 3.1\% bet more than HK\$500, 2.8\% staked HK\$100-\$199, 2\% between HK\$300$399,1.7 \%$ spent $\mathrm{HK} \$ 200-\$ 299$, and $0.6 \%$ staked HK\$400-\$499 per week. On average, social gamblers wagered less than HK\$100 a week, excessive gamblers doubled the wager size (to at least $\mathrm{HK} \$ 200$ a week). Problem and pathological gamblers staked significantly more money than social gamblers $(t=3.12, p<0.01)$.

Almost a quarter of the players (24\%) borrowed money to finance their gambling activities, $10.5 \%$ from peers, $5.7 \%$ from parents, $4.6 \%$ from family members (mainly from elder siblings), 1.8\% from relatives and 1.3\% from neighbors. However, results of statistical analysis did not indicate that those who had borrowed money to gamble were more likely to have gambling problems.

\section{Gender differences in gambling involvement and pathological gambling}

Males were twice as likely as females to gamble; the 2.1-fold gender difference was statistically significant $\left(\chi^{2}(36)=63.7, p<0.01\right)$. Boys were also significantly more vulnerable to pathological and problem gambling than girls $\left(71.2 \%\right.$ vs $28.8 \% ; \chi^{2}(1)$ $=8.3, p<0.01$ ).

\section{Gambling preferences}

For the entire sample of gamblers $(N=601), 85.2 \%$ wagered on mahjong and card games, 31.4\% on Mark Six lotteries at the Hong Kong Jockey Club (HKJC), 29.1\% on soccer matches, $7.2 \%$ on horse races at the HKJC, $5 \%$ on soccer betting and $4.7 \%$ on other sports betting with illegal bookmakers. In all, 3.7\% bet on Internet casino games, $2.2 \%$ on Macau casino table games, and $1.5 \%$ on various games provided on gambling cruises.

Male social gamblers predominated in many forms of gambling including Macau casino gambling $(100 \%)$, soccer betting with illegal bookmakers $(100 \%)$, gambling cruises $(90 \%)$, betting on soccer matches among peers $(91.2 \%)$, soccer $(89.7 \%)$ and horse race betting $(88.9 \%)$ at the HKJC, sports betting with illegal bookmakers $(88.9 \%)$, Internet casino gambling $(87 \%)$, cards and mahjong $(73.3 \%)$, and Mark Six lotteries at the HKJC (64.3\%). Female social gamblers preferred the Mark Six lotteries $(35.7 \%)$ at HKJC, cards and mahjong (26.7\%), Internet casino games $(13 \%)$, sports betting with illegal bookmakers $(11.1 \%)$, betting on soccer matches $(10.3 \%)$ and horse races $(11.1 \%)$ at the HKJC, gambling cruises $(10 \%)$ and soccer betting among peers $(8.8 \%)$.

Male excessive gamblers also outnumbered their female counterparts in soccer betting with illegal bookmakers $(100 \%)$, gambling cruises $(100 \%)$, on soccer 
$(85.7 \%)$, lotteries $(83.3 \%)$ and horse races $(83.3 \%)$ at the HKJC, soccer betting among peers $(81.8 \%)$, sports betting with illegal bookmakers $(71.4 \%)$, Internet casino games (71.4\%), and Macau casino gambling $(71.4 \%)$. Gender difference was not evident for cards and mahjong (boys $57.6 \%$; girls $42.4 \%$ ).

\section{Reasons for gambling participation}

Male social gamblers gambled to socialize with peers $(97.1 \%)$, to seek excitement $(85.4 \%)$, to escape problems $(76.1 \%)$, to win money $(76.1 \%)$, to relieve boredom $(75.7 \%)$, to be challenged $(74.4 \%)$, to kill time $(70.7 \%)$, and to cope with familial gambling $(56.2 \%)$.

The reasons for gambling given by female social gamblers included: family influence $(43.8 \%)$, killing time $(29.3 \%)$, meeting challenges $(24.3 \%)$, alleviating boredom $(24.3 \%)$, winning money $(23.9 \%)$, escaping problems $(15.4 \%)$, seeking excitement $(14.6 \%)$ and socializing with peers $(2.9 \%)$.

The pathological and problem gamblers reported gambling to escape problems $(80.8 \%)$, to relieve boredom $(76.9 \%)$, to pass time $(75 \%)$, to win money $(61.5 \%)$, to socialize with peers $(50 \%)$, to meet challenges $(15.4 \%)$, to seek excitement $(11.5 \%)$ and to cope with family influence $(7.7 \%)$. No significant differences were found in the reasons reported by male and female problem gamblers.

\section{Age at which gambling started}

For the entire sample of gamblers, $75.5 \%$ made their first bet aged 6-14 years, $21.4 \%$ when aged $15-16$ years, and $3.1 \%$ before the age of 6 years. On average, the social gamblers started gambling at 10.5 years (mean age). Most of the male social gamblers $(64.7 \%)$ began gambling when aged $6-11$ years, $12.5 \%$ at $15-16$ years, $11.4 \%$ at $12-14$ years, and another $11.4 \%$ under 6 years. Many female social gamblers $(60.4 \%)$ started gambling when aged $6-11$ years, $16.7 \%$ at $15-16$ years, $14.6 \%$ at $12-14$ years, and $8.3 \%$ aged below 6 years.

Only $9.6 \%$ of the pathological and problem gamblers started gambling when aged $15-16$ years; $90.4 \%$ had begun well before they were 15 years old, $9.6 \%$ before the age of 6 years. The mean age at which the pathological and problem gamblers made their first bet was 9.25 years. A great majority of the male pathological and problem gamblers $(91.9 \%)$, and $86.7 \%$ of their female counterparts made their first bet before they were 15 years old.

Many young gamblers were first introduced to gambling activities by their parents $(40.5 \%)$, their friends $(33.9 \%)$ and other family members such as elder siblings $(22.3 \%)$ and neighbors (3.3\%). More than one-fifth $(22.9 \%)$ reported having parents with gambling problems, and $16.7 \%$ had peers distressed by gambling problems.

\section{Strategies for placing bets and transferring payments}

There are only three types of gambling activities operated by the HKJC. Overall (data of the three different forms of gambling were merged), $44.7 \%$ of underage gamblers were assisted to place bets and transfer gambling payments by their parents, $19.7 \%$ by their peers and $14.1 \%$ by adult family members (mainly elder siblings). As high as $25.3 \%$ risked being caught entering and placing bets at the 
HKJC off-course betting branches.

More than half of the gamblers (55.2\%) reported that their parents helped them transfer gambling payments on lotteries, horse races $(50.8 \%)$ and soccer matches $(28 \%)$. Friends and classmates provided help in laying wagers on soccer matches $(30.7 \%)$, horse races $(16.4 \%)$ and lotteries $(12.1 \%)$. Adult family members transferred gambling payments for underage teens on soccer betting $(16 \%)$, horse racing $(14.8 \%)$ and lotteries $(11.5 \%)$. A quarter of the young gamblers $(25.3 \%)$ went directly to the HKJC betting stations to make their bets on soccer matches, lotteries $(21.3 \%)$ and horse races $(18 \%)$.

\section{Mental health of the participants and the juvenile gamblers}

The mean GHQ-12 scores for the total sample was $1.36(S D=2.1)$. A quarter of the social gamblers $(26.4 \%, n=145)$ obtained a score of 3 or more on the GHQ-12 (Goldberg, 1972). They could be classified as mentally unhealthy. More than half of the pathological and problem gamblers $(63.5 \%, n=32)$ scored above the threshold of 3 (mean score $=4.1 ; S D=2.4$ ). They experienced significantly higher levels of mental distress than the social gamblers $(t=-3.79, p<0.01)$. They reported symptoms of general psychiatric impairment including being depressed (51.4\%), losing selfconfidence $(42.9 \%)$, feeling under strain $(40 \%)$, sleeping problems $(37.1 \%)$, lack of concentration $(34.3 \%)$, could not overcome difficulties $(34.3 \%)$, being unable to face problems $(31.4 \%)$, feeling unhappy $(28.6 \%)$, failing to make decision $(25.7 \%)$ and finding oneself worthless or useless $(22.9 \%)$.

\section{Correlates of pathological and problem gambling}

Table 1 summarizes the correlations (Pearson product moment) derived from the sub-samples of underage gamblers. Problem and pathological gambling was significantly correlated with age $(r=0.44, p<0.01)$, gambling frequency $(r=0.41, p$ $<0.001)$, gender $(r=0.33, p<0.01)$, age of first gambling $(r=-0.31, p<0.05)$, mental health disturbances $(r=0.25, p<0.001)$, parental gambling problems $(r=0.21, p<$ $0.01)$ and peers having gambling problems $(r=0.18, p<0.05)$.

Table 1. Correlations between DSM-IV-MR-J scores and demographic, behavioral, social and mental health variables

\begin{tabular}{ll}
\hline Variable & DSM-IV-MR-J scores \\
\hline Age & $0.44^{* *}$ \\
\hline Gambling frequency & $0.41^{* * *}$ \\
\hline Gender & $0.33^{* *}$ \\
\hline Early gambling initiation & $-0.31^{*}$ \\
\hline General Health Questionnaire scores & $0.25^{* * *}$ \\
\hline Parents having gambling problems & $0.21^{* *}$ \\
\hline Peers having gambling problems & $0.18^{*}$ \\
\hline
\end{tabular}

${ }^{*} p<0.05,{ }^{* *} p<0.01,{ }^{* * *} p<0.001$, (two-tailed). 


\section{Discussion}

\section{Increase in estimate of gambling participation}

This study showed that gambling activities were popular among underage high school students in Hong Kong. Sixty percent of those surveyed had gambled over the past 12 months, and $30.9 \%$ of these underage gamblers staked at least once a week. This gambling prevalence estimate was comparable to the 60 to $80 \%$ rates reported in many western studies (Delfabbro et al., 2005; Griffiths, 1989; Gupta \& Derevensky, 1998a; Jacobs, 2000; Olason et al., 2006; Turchi \& Derevensky, 2006; Welte et al., 2008).

The rate noted in the present study was higher than those marked in previous local studies on gambling behavior among adolescent students. More research is needed to keep track of changes in gambling involvement among underage teens.

\section{Increase in prevalence rate of pathological gambling}

This study indicated that $3.4 \%$ and $1.8 \%$ of the total sample met the DSM-IV criteria for pathological and problem gambling, respectively. The prevalence rate of pathological and problem gambling fell within the range of 2 to $9 \%$ reported in many western studies (e.g., Delfabbro et al., 2005; Fisher, 1999; Griffiths, 1995; Gupta \& Derevensky, 1998a; Moore \& Ohtsuka, 1997; Shaffer \& Hall, 1996).

When the 2001 (Hong Kong Polytechnic University) and 2005 region-wide estimates (University of Hong Kong) were compared with the past-year prevalence rate of pathological gambling reported in this survey (3.4\%), significant increases of $0.8 \%$ and $2.1 \%$ respectively were noted. Since similar instruments (all DSM-IV criteria screens) were used in these surveys, comparisons of estimates have been enhanced. Nevertheless, it is necessary to conduct more research to confirm whether pathological gambling among adolescents is increasing (particularly among the underage teens), and if so determine the reasons.

\section{Gambling motives of pathological and problem gamblers}

The five most frequently reported reasons for gambling given by the pathological and problem gamblers were escaping problems $(80.8 \%)$, relieving boredom $(76.9 \%)$, killing time $(75 \%)$, winning money $(61.5 \%)$, and socializing with peers $(50 \%)$. Problematic gamblers tended to use gambling as a pastime with peers so as to cope with personal problems (Griffiths, 1995, 2002) and to seek mood modification (Jacobs, 2004; Gillespie et al., 2007).

\section{Gender differences in gambling behavior}

Consistent with past research results, this study confirmed gender differences in gambling involvement and excessive gambling (e.g., Desai et al., 2005; Griffiths, 1991; Gupta \& Derevensky, 1998a; Jacobs, 2000, 2004; National Research Council, 1999). Underage adolescent boys in Hong Kong were more likely than girls to gamble $(67.6 \%$ vs $32.4 \%)$ and to begin gambling early. Most of male social gamblers $(87.5 \%)$ and $83.3 \%$ of the females first engaged in gambling activities before the age of 15 years. A great majority of the male pathological and problem gamblers (91.9\%) and $86.7 \%$ of their female counterparts placed their first bet well before 15 . These findings suggest prevention programs should start early and prior to adolescence, 
especially for boys.

Boys outnumbered girls in all forms of gambling listed in the questionnaire. Gender differences in gambling preferences were noted, with boys more tempted to games of skill (soccer, sports and horse betting), and girls to lottery tickets and social gambling (mahjong and card games). Boys were also more likely to wager with illegal bookmakers than girls.

The two sexes were motivated to gamble for different reasons. Females were lured by familial gambling $(43.8 \%)$, and used gambling to pass time $(29.3 \%)$. Boys sought social interactions with friends $(97.1 \%)$, excitement $(85.4 \%)$, escape from problems $(84.6 \%)$ and money $(76.1 \%)$.

Compared with western research data (e.g., Jacobs, 2004; National Research Council, 1999), this study found less pronounced gender differences in severe gambling problems. Boys were 2.5 times more likely than girls to develop pathological or problem gambling; the ratio is smaller than the range of $3: 1$ to $5: 1$ listed by Jacobs (2004).

\section{Transfer of gambling payments}

Similar to their western counterparts' experience (Felsher, Derevensky, \& Gupta, 2003), underage gamblers in Hong Kong (25.3\%) had little difficulty in gaining access to betting branches to make a wager and transfer gambling payments. Gambling provider should strictly enforce age verification procedures to prohibit any youth under 18 years old being admitted to such venues and make wagers. Since accessibility and geographical location of gambling venues also represent significant risk factors (Griffiths, 1999), the HKJC betting branches should not be near schools.

While a quarter of the underage gamblers entered the betting shops to place their bets, a larger proportion relied on parents $(44.7 \%)$ and other adult family members $(14.1 \%)$ to transfer gambling payments. It seems clear that prevention of underage gambling must involve parents and ideally should target the family system as a whole. Existing preventive and awareness programs rarely target the entire family system. If adults including parents and elder family members refused to help underage persons in transferring gambling payments, it is possible that gambling involvement and excessive gambling could be drastically reduced. Public education should include warnings against provision of parental and familial assistance to minors to place bets.

\section{Association between problem gambling and gambler's gender and age}

The survey confirmed that the two most common socio-demographic factors associated with adolescent problem gambling were male gender and the gambler's age. Replicating earlier research results (Desai et al., 2005; Griffiths, 1991; Gupta \& Derevensky, 1998a; National Research Council, 1999; Wong, 2010), boys dominated the ranks of underage pathological and problem gamblers (71.2\% vs $28.8 \%)$.

Older teens from higher grades were more susceptible to excessive gambling. Being taller and having a more mature appearance, they had a better chance of being admitted to HKJC betting branches without age checks. They might also have more pocket money available for gambling because they were relatively more likely 
to receive greater amounts of family spending money and have income from parttime jobs.

\section{Association between problem gambling and early gambling}

Abundant research evidence shows an association between problem gambling and starting to gamble at an early age, often before reaching 10 years old (e.g., Dickson, Derevensky, \& Gupta, 2004; Griffiths, 1995; Gupta \& Derevensky, 1998a; Jacobs, 2000; National Research Council, 1999; Winters, Stinchfield, Botzet, \& Anderson, 2002; Wong, 2010; Wynne et al., 1996). This study also confirms such a relationship between early gambling and severe gambling problems. Pathological and problem gamblers made their first bet at a mean age of 9.25 years, whereas social gamblers began wagering at a mean age of 10.5 years. The survey indicates that early prevention should be implemented (before 9 years old) and continued throughout the adolescence years.

\section{Association between problem gambling and gambling frequency}

Consistent with past research data (e.g., Vitaro, Brendgen, Ladouceur, \& Tremblay, 2001), pathological and problem gambling was positively correlated with gambling frequency. Underage pathological and problem gamblers wagered more frequently than the recreational players (5.8 times as often).

\section{Association between problem gambling and mental health problems}

There was a significant positive association between the severity of gambling problems and the symptoms of psychiatric impairment. Excessive gamblers scored significantly higher on the Chinese GHQ-12 than the social gamblers. These results replicate past research data which suggested that mental health problems including anxiety, depression, self-harm behavior and suicidal ideation correlate with problem gambling among adolescents (Delfabbro et al., 2005; Gupta \& Derevensky, 1998a; Nower et al., 2004; Wynne et al., 1996). These young problem gamblers with co-morbid psychiatric and emotional disturbances need further clinical assessment and even treatment. It may be beneficial to include a brief screening of mental health problems in the treatment of adult and adolescent gamblers.

\section{Association between problem gambling and influence from parents and peers}

This survey revealed underage excessive gambling correlated with having parents and peers being distressed by gambling problems. Previous research has documented the impact of peers (Langhinrichsen-Rohling, Rohde, Seeley, \& Rohling, 2004; Vitaro et al., 2001) and parents on adolescent gambling problems (Fisher, 1993; Griffiths, 1995; Gupta \& Derevensky, 1997; Ladouceur \& Mireault, 1988; Wood \& Griffiths, 1998). Children spontaneously become engaged in gambling activities going on in their family, school and other natural social environments (Jacobs, 2004). They simply imitate the gambling behavior of their role models, particularly their parents and close friends.

For many Chinese children, their first exposure to gambling is playing mahjong and cards in a happy family context. The study revealed that Chinese parents not 
only introduced the underaged to gambling activities $(40.5 \%)$, they also offered them help in placing bets $(44.7 \%)$ at both legal and illegal outlets, and even lent money to their children in placing wagers $(5.7 \%)$. Furthermore, more than one-fifth $(22.9 \%)$ of juvenile gamblers reported having parents and friends having to endure gambling problems. Research data consistently indicate higher rates of excessive gambling are found in teens who report parental gambling problems (Jacobs, 2000; Winters et al., 1993a). This study replicates these earlier research results, confirming that adolescent gambling addiction is related to parental compulsive gambling because this group is more likely to gamble.

Peer influence is a significant risk factor for adolescent gambling problems (Gupta \& Derevensky, 1998a; Stinchfield \& Winters, 1998). In this study, peers acted as gambling coaches $(33.9 \%)$, and provided help $(19.7 \%)$ and money $(10.5 \%)$ to the underage gamblers for their wagers. A considerable proportion of these underage gamblers $(16.7 \%)$ disclosed having peers with gambling problems. This study implies that they have higher risk of becoming excessive gamblers than those who did not report peer gambling problems. Parental education and public health programs may help promote awareness and coping with potentially harmful social influences in gambling.

The correlational results were consistent with past research findings. The evidence-based information derived from this study is useful for identifying underage problem gamblers so that further thorough assessment and early treatment could be provided. Secondary preventive programs should also target such high-risk teens.

\section{Conclusion}

The study helped expand our understanding of gambling behavior among underage adolescents. It replicated previous research results, showing gender differences with respect to the frequency and onset of gambling behavior, choices of games, reasons for participation, and prevalence of gambling involvement and problem gambling. Future research may further investigate gender differences in correlates and prediction of problem gambling among the underage adolescents. The small number of female pathological and problem gamblers in this study hampered such attempts.

This study provided support for associations between adolescent problem gambling and a host of demographic, social, behavioral and mental health variables. However, data generated from the present study did not permit causal inferences, further methodological improvements (longitudinal and prospective research designs) are needed in future etiological research.

The study also indicated major areas of concern for future research. For example, pathological and problem gambling was associated with psychiatric impairment. Further investigation and timely interventions are required. A considerable proportion of the underage students $(9.7 \%)$ and predominantly male gamblers participated in illegal gambling activities. Future research could explore how and why teens are involved in illegal gambling, and the negative consequences associated with the activity. Government and policy makers should review existing gambling policy and intervention strategies to address issues related to illicit and 
problem gambling among underage adolescents.

Interestingly, most of the survey results reveal similarities rather than contrasts with findings from earlier western adolescent studies as far as gender differences, gambling involvement and correlates of problem gambling are concerned. These findings merit future cross-cultural research and comparisons to promote better insights into gambling behavior among Asian and Western adolescents.

\section{Acknowledgments}

The author thanks the survey participants. Appreciation is also due to anonymous reviewers.

\section{References}

American Psychiatric Association. (1994). Diagnostic and statistical manual of mental disorders $\left(4^{\text {th }}\right.$ ed). Washington, DC: American Psychiatric Association.

Adlaf, E. M., \& Ialomiteanu, A. (1999). Prevalence of problem gambling in adolescents: Findings from the 1999 Ontario Students Drug Use Survey. Canadian Journal of Psychiatry, $45,752-755$.

Banks, M. H., Clegg, C. W., Jackson, P. R., Kemp, N. J., Stafford, E. M., \& Wall, T. D. (1980). The use of the General Health Questionnaire as an indicator of mental health in occupational studies. Journal of Occupational Psychology, 53, 187-194.

Delfabbro, P., Lahn, J., \& Grabosky, P. (2005). Further evidence concerning the prevalence of adolescent gambling and problem gambling in Australia: A study of the ACT. International Gambling Studies, 5, 209-228.

Derevensky, J., \& Gillespie, M. (2005). Keynote address: Gambling in Canada eCommunity. International Journal of Mental Health and Addiction, 3, 3-14.

Desai, R. A., Maciejewski, P. K., Pantalon, M. V., \& Potenza, M. N. (2005). Gender differences in adolescent gambling. Annals of Clinical Psychiatry, 17, 249-258.

Dickson, L., Derevensky, J. L., \& Gupta R. (2004). Harm reduction for the prevention of youth gambling problems: Lessons learned from adolescent high-risk prevention programs. Journal of Adolescent Research, 19, 233-263.

Felsher, J., Derevensky, J., \& Gupta, R. (2003). Parental influences and social modeling of youth lottery participation. Journal of Community and Applied Social Psychology, 13, 361-377.

Fisher, S. E. (1993). Gambling and pathological gambling in adolescence. Journal of Gambling Studies, 9, 277-287.

Fisher, S. E. (1999). A prevalence study of gambling and problem gambling in British adolescents. Addiction Research, 7, 509-538.

Fisher, S. E. (2000). Developing the DSM-IV-MR-J criteria to identify adolescent problem gambling in non-clinical populations. Journal of Gambling Studies, 16, 253-273.

Gillespie, M. A. M., Derevensky, J., \& Gupta, R. (2007). Adolescent problem gambling: Developing a gambling expectancy instrument. Journal of Gambling Issues, 19, 51-68.

Goldberg, D. P. (1972). The detection of psychiatric illness by questionnaire. Maudsley Monograph No. 21. Oxford: Oxford University Press.

Goldberg, D. P., Gater, R., Sartorius, N., Ustun, T. B., Piccinelli, M., Gureje, O., \& Rutter, C. (1997). The validity of two versions of the GHQ in the WHO study of mental illness in general health care. Psychological Medicine, 27, 191-197.

Griffiths, M. D. (1989). Gambling in children and adolescents. Journal of Gambling Behavior, 5, 66-83.

Griffiths, M. D. (1991). Amusement machine playing in childhood and adolescence: A comparative analysis of video games and fruit machines. Journal of Adolescence, 14, 53-73. 
Griffiths, M. D. (1995). Adolescent gambling. London: Routledge.

Griffiths, M. D. (1999). Gambling technologies: Prospects for problem gambling. Journal of Gambling Studies, 15, 265-283.

Griffiths, M. D. (2002). Gambling and gaming addictions in adolescence. Oxford: British Psychological Society, Blackwells.

Griffiths, M. D., \& Wood, R. T. (2000). Risk factors in adolescence: The case of gambling, video game playing, and the Internet. Journal of Gambling Studies, 12, 375-394.

Gupta, R., \& Derevensky, J. (1997). Familial and social influences on juvenile gambling behavior. Journal of Gambling Studies, 13, 179-192.

Gupta, R., \& Derevensky, J. L. (1998a). Adolescent gambling behavior: A prevalence study and examination of the correlates associated with problem gambling. Journal of Gambling Studies, 14, 319-345.

Gupta, R., \& Derevensky, J. L. (1998b). An empirical examination of Jacobs' General Theory of Addictions: Do adolescent gamblers fit the theory? Journal of Gambling Studies, 14, 17-49.

Hodge, G. R. (1994). Adolescent anxiety, distress and coping: A study of senior school students and higher school certificate examination stress. Doctor of Education Thesis: The University of New South Wales.

Hong Kong Polytechnic University. (2001). A study on Hong Kong people's participation in gambling activities. Hong Kong: Hong Kong Polytechnic University.

Jacobs, D. F. (1993). A review of juvenile gambling in the United States. In W. R. Eadington, \& J. A. Cornelius (Eds.). Gambling behavior and problem gambling (pp. 431-441). Reno, UV: University of Nevada Press.

Jacobs, D. F. (2000). Juvenile gambling in North America: An analysis of long-term trends, future prospects. Journal of Gambling Studies, 16, 119-152.

Jacobs, D. F. (2004). Youth gambling in North America: Long term trends, future prospects. In J. Derevensky \& R. Gupta (Eds.), Gambling problems in youth: Developmental and applied perspectives (pp. 1-26). New York: Kluwer Academic/Plenum Publishers.

Ladouceur, R., Dubé, D., \& Bujold, A. (1994). Prevalence of pathological gambling and related problems among college students in the Quebec metropolitan area. Canadian Journal of Psychiatry, 39, 289-293.

Ladouceur, R., \& Mireault, C. (1988). Gambling behaviors among high school students in the Quebec area. Journal of Gambling Behavior, 4, 3-12.

Langhinrichsen-Rohling, J., Rohde, P., Seeley, J. R., \& Rohling, M. L. (2004). Individual, family, and peer correlates of adolescent gambling. Journal of Gambling Studies, 20, 23-46.

Moore, S. M., \& Ohtsuka, K. (1997). Gambling activities of young Australians: Developing a model of behaviour. Journal of Gambling Studies, 13, 207-236.

National Research Council. (1999). Pathological gambling: A critical review. Washington, DC: National Academy Press.

Nower, L., Gupta, R., Blaszczynski, A., \& Derevensky, J. (2004). Suicidality and depression among youth gamblers: A preliminary examination of three studies. International Gambling Studies, 4, 69-80.

Olason, D. T., Skarphedinsson, G. A., Jonsdottir, J. E., Mikaelsson, M., \& Gretarsson, S. (2006). Prevalence estimates of gambling and problem gambling among 13- to 15-yearold adolescents in Reykjavik: An examination of correlates of problem gambling and different accessibility to electronic gambling machines in Iceland. Journal of Gambling Issues, 18, 39-55.

Shaffer, H. J., \& Hall, M. N. (1996). Estimating the prevalence of adolescent gambling disorders: A quantitative synthesis and guide toward standard gambling nomenclature. Journal of Gambling Studies, 12, 193-214.

Shaffer, H. J., \& Hall, M. N. (2001). Updating and refining prevalence estimates of disordered 
gambling behaviour in the United States and Canada. Canadian Journal of Public Health, 92, 168-172.

Stinchfield, R. D., \& Winters, K. C. (1998). Gambling and problem gambling among youth. Annals of American Academy of Political and Social Science, 556, 172-185.

Turchi, R. M., \& Derevensky, J. L. (2006). Youth gambling: Not a safe bet. Current Opinion in Pediatrics, 18, 454-458.

University of Hong Kong. (2005). A study on Hong Kong people's participation in gambling activities. Hong Kong: The University of Hong Kong.

Vitaro, F., Brendgen, M., Ladouceur, R., \& Tremblay, R. E. (2001). Gambling, delinquency and drug use during adolescence: Mutual influences and common risk factors. Journal of Gambling Studies, 17, 171-190.

Volberg, R., \& Moore, W. (1999). Gambling and problem gambling among adolescents in Washington State: A six-year replication study, 1993-1999. Report to the Washington State Lottery. Albany, New York: Gemini Research.

Welte, J. W., Barnes, G. M., Tidwell, M. C., \& Hoffman, J. H. (2008). The prevalence of problem gambling among U.S. adolescents and young adults: Results from a national survey. Journal of Gambling Studies, 24, 119-133.

Winters, K. C., Stinchfield, R. D., Botzet, A., \& Anderson, N. (2002). A prospective study of youth gambling behaviors. Psychology of Addictive Behaviors, 16, 3-9.

Winters, K. C., Stinchfield, R. D., \& Fulkerson, J. (1993a). Towards the development of an adolescent gambling problem severity scale. Journal of Gambling Studies, 9, 63-84.

Winters, K. C., Stinchfield, R. D., \& Fulkerson, J. (1993b). Patterns and characteristics of adolescent gambling. Journal of Gambling Studies, 9, 371-386.

Wong, I. L. K. (2006). A study of gambling and problem gambling among high school students. Hong Kong: Hong Kong Polytechnic University.

Wong, I. L. K. (2010). Internet gambling: A school-based survey among Macau students. Social Behavior and Personality, 38, 365-372.

Wong, I. L. K., \& So, M. T. (2004). A study of adolescent gambling behavior. Hong Kong: Hong Kong Polytechnic University.

Wood, R. T. A., \& Griffiths, M. D. (1998). The acquisition, development and maintenance of lottery and scratchcard gambling in adolescence. Journal of Adolescence, 21, 265-273.

Wynne, H., Smith, G., \& Jacobs, D. (1996). Adolescent gambling and problem gambling in Alberta. Edmonton, Alberta: Alberta Alcohol and Drug Abuse Commission. 